\title{
LEVEL OF KNOWLEDGE AND NURSING PRACTICES ON DIABETIC FOOT MANAGEMENT
}

\author{
Muhamet Kadrija $^{1 *}$, Fatmira Karabollaj ${ }^{2}$ \\ I*University of Gjakova "Fehmi Agani", Gjakova, Kosova; \\ ${ }^{1 *}$ Corresponding Author Muhamet Kadrija, e-mail: muhamet.kadrija@uni-gjk.org;
}

Received November 2021; Accepted December 2021; Published January 2022;

DOI: https://doi.org/10.31407/ijees12.111

\begin{abstract}
Entry and purpose: Diabetes is one of the main causes of mortality and impossibility. Diabetic foot is a more frequent complication. Nurses have an essential role in preventing diabetic foot problems, in caring for and educating patients at risk for diabetic foot. Thus, the high level of knowledge and nursing practices will always provide better care for the patient. The aim of this study is to assess the knowledge and practices of nurses in diabetic foot management in the city of Gjakova. Methodology: This is a cross-sectional study, carried out during the June-August 2021 time period. As a population for study, 120 nurses are included. For this study I used a selfadministered questionnaire. The data was worked out in the SPSS statistical package. Results: Based on the results of the study on the impact of demographic factors, it resulted in education, division and experience at work affecting the level of practices and knowledge on diabetic foot management ( $\mathrm{P}<$ value 0.05$)$. In our study, only $15 \%$ of nurses were trained in diabetic foot care. Asked if they needed or wanted to take other training, 78\% expressed interest. In general, nurses have good knowledge in diabetic foot management: in assessing knowledge of risk factors in their foots, as well as in diabetic foot prevention. $52 \%$ of nurses stated that they needed training. Conclusion: Nurses must participate continuously in training to learn new techniques, which are efficient in diabetic foot management.
\end{abstract}

Key words: diabetes, diabetic foot, management, nurse. 